\title{
Engaging children in geosciences through storytelling and creative dance
}

\author{
Ana Matias ${ }^{1}$, A. Rita Carrasco ${ }^{1}$, Ana A. Ramos ${ }^{2}$, and Rita Borges ${ }^{2}$ \\ ${ }^{1}$ Centre for Marine and Environmental Research (CIMA), Universidade do Algarve, 8000 Faro, Portugal \\ ${ }^{2}$ Centro Ciência Viva de Tavira, 8800 Tavira, Portugal
}

Correspondence: Ana Matias (ammatias@ualg.pt)

Received: 1 October 2019 - Discussion started: 7 October 2019

Revised: 8 May 2020 - Accepted: 19 May 2020 - Published: 6 July 2020

Abstract. Natural sciences have traditionally been disseminated in outreach activities as formal, one-way presentations. Nevertheless, innovative strategies are being increasingly developed using arts, gaming, and sketching, amongst others. This work aimed at testing an alternative and innovative way to engage non-expert audiences in ocean and coastal geology through a combination of scientific concept explanations and creative dancing. An informal education activity focusing on ocean dynamics was designed for 10-yearold students. It combines coastal science concepts (wind, waves, currents, and sand), storytelling techniques (narrative arc), and creative dance techniques (movement, imaginative play, and sensory engagement). A sequence of six exercises was proposed, starting with the generation of offshore ocean waves and ending with sediment transport on the beach during storm/fair-weather conditions. Scientific concepts were then translated into structured creative movements, within imaginary scenarios, and accompanied by sounds or music. The activity was performed six times with a total of 112 students. It was an inclusive activity given that all students in the class participated, including children with several mild types of cognitive and neurological impairment. The science and art activity aroused emotions of enjoyment and pleasure and allowed for effective communication between scientists and school community. Moreover, the results provide evidence of the activity's effectiveness in engaging children and developing their willingness to further participate in similar activities.

\section{Introduction}

The act of dissemination (and communication) is part and parcel of doing research. The main vehicle of scientific information lies within the scientific community through peerreviewed periodicals generally focused on specific research areas and directed at well-circumscribed, specialized audiences (e.g. Gravina et al., 2017). Nevertheless, there is still a gap in the effectiveness of such communication with the general public, with scientists often seen as being trapped in an ivory tower (e.g. Baron, 2010) and commonly using scientific jargon that is hard for the common citizen to understand. There is a vast range of approaches for engaging public audiences with scientific concepts (Bultitude, 2011); Mesure (2007) identified over 1500 active initiatives within the UK alone. There are three main forms of media used in science communication with the public: traditional journalism, live or face-to-face events, and online interactions. According to Bultitude (2011), live events have the advantage of being more personal, allowing scientists to better control the content, engendering two-way communication, and involving other external organizations with complementary expertise through partnering can be done. The disadvantages of live events are limited audience reach; they are resource intensive and lead to low sustainability of activities, and they can be criticized for only attracting audiences with a preexisting interest.

According to Kim (2012), effective communication of science lies in the processes of public engagement with a problem or an issue relative to science because "the processes of engagement develop from the acts of exposing and focusing attention to the act of cognizing". Science journalism and 
classroom instruction seem to hold strongly to the traditional learning theory paradigm that mere exposure to scientific knowledge would lead to scientific literacy and public understanding (Kim, 2012). In this work, engagement will not be used in the same sense as public engagement with science, which has a specific meaning that refers to activities, events, or interactions characterized by mutual learning among people of varied backgrounds, scientific expertise, and life experiences who articulate and discuss their perspectives, ideas, knowledge, and values in response to scientific questions or science-related controversies (McCallie et al., 2009). Here, in terms of informal science education, engagement is a loosely defined term referring to behaviours that demonstrate interest in, or interaction with, science-related activity or experience.

Recent work indicates that storytelling and narrative can help communicate science to non-experts within the wider context of framing as an important feature of public outreach (Martinez-Conde and Macknik, 2017). Furthermore, strategies fusing arts and science (e.g. using games, poetry, music, painting, and sketching) are becoming a favoured medium for conveying science to the public (e.g. Cachapuz, 2014; Von Roten and Moeschler, 2007; Gabrys and Yusoff, 2012). Collaborative projects between artists and science, technology, engineering, and mathematics (STEM) fields are not new, with renewed interest over the last decades (Heras and Tàbara, 2014); hence, the collection of science, technology, engineering, arts, and mathematics (STEAM) is increasingly replacing the traditional STEM designation. A maturing body of work indicates that the arts can deeply engage people by focusing on the affective domain of learning (i.e. engagement, attitude, or emotion) rather than on the cognitive domain (i.e. understanding, comprehension, or application), which is often emphasized in science education (Friedman, 2013). Therefore, science communication through art brings science to the public in ways that are engaging, instructive, artistic, and, always, content-driven (Schwartz, 2014). Examples of science and art projects include theatre as a way of communicating coastal risk (Brown et al., 2017), hiphop dance as a way of learning ecology (Wigfall, 2015), or art installations inspired in neuroscience laboratories (Lopes, 2015). Varelas et al. (2010) observed that, while participating in a play representing STEM concepts, students engaged in understanding science from multiple perspectives. Embodied exercises situate abstract concepts in a concrete context, thus relating intangible ideas with corporeal information, and so rich multimodal distributed neural representations are forged (Hayes and Kraemer, 2017). Chang (2015) compiled an environmental science artwork database that consisted of 252 artworks, but only $4 \%$ included artistic mediums like poetry, dance, and performances; the majority was from the visual arts domain. Good examples of STEM education through creative dance can be found in Landalf (1997), for approaching earth sciences, and in Abbott (2013), for approaching mathematics. Creative dance is thus one mode of learning that involves using the body and the senses to gather informa- tion, communicate, and demonstrate conceptual understanding (Cone and Cone, 2012).

In Portugal, Afonso et al. (2013) reported that science teaching appeals to memorization of data and lacks abstract conceptual understanding. Geology education, in particular, is mostly associated with memorization (e.g. minerals and rocks), which drives students away from geosciences. Moreover, science communication with the general public only occasionally covers geosciences when compared to other sciences such as astronomy, health, or biology, as can be deducted from an analysis of most newspapers' records (consultation of the science section records of the Portuguese newspaper "Público"), although good examples can be found in science communication literature (e.g. Pedrozo-Acuña et al., 2019).

Coastal and marine geology have traditionally been disseminated in science outreach activities in the form of formal, one-way presentations or, at best, field trips or lab experiences. The success of outreach actions and education programmes requires knowing and understanding different audiences and strategizing how to reach them. So, efforts are made now to improve marine science literacy with accurate and appealing techniques that strengthen the learner's emotional connection to the ocean. The Intergovernmental Oceanographic Commission (IOC) of UNESCO states that only through ocean literacy will it be possible to create an educated society capable of making informed decisions and caring for the preservation of the ocean's health (Santoro et al., 2017). In this context, effective geoscience communication activities addressing Principle 2 of ocean literacy defined by the IOC, namely that "The ocean and life in the ocean shape the features of the Earth", are in great need. This is aligned with the UNESCO Sustainable Development Goal (SDG) 14 - "Conserve and sustainably use the oceans, seas, and marine resources for sustainable development", and geoscience communication activities that address this issue are also in great need.

Aligning with SDG 14 and IOC Principle 2 of ocean literacy, the objective of this work was to develop an alternative and innovative activity to engage children in geosciences by combining scientific concept transmissions with creative dance. Moreover, this work intended to provide additional arguments about the importance of arts (dance) and communication techniques (storytelling) in the engagement and effectiveness of geoscience programmes and develop the students' willingness to participate in similar activities. Described activities were performed within the framework of the outreach task of a research project devoted to the evolution and resilience of barrier island systems (the EVREST project). The EVREST project (more information at https: //evrest.cvtavira.pt/, last access: 26 June 2020) identified natural and human processes that contributed to the Ria Formosa (south of Portugal) barrier island evolution (Kombiadou et al., 2019b) and developed a framework to quantify barrier island resilience (Kombiadou et al., 2018, 2019a). The project, 


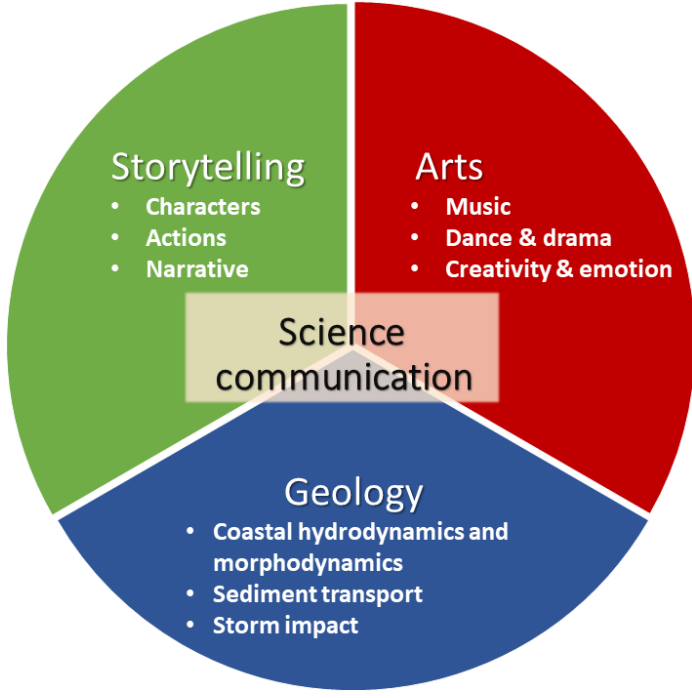

Figure 1. Scheme summarizing the elements from each component to develop the interdisciplinary research.

led by a research centre (CIMA - Universidade do Algarve), also included the Tavira Ciência Viva Science Centre (devoted to disseminating science to the public), the partner responsible for facilitating the bridge between researchers and primary school students.

\section{Development of the activity "The Sea Rolls the Sand"}

An interdisciplinary activity was developed by merging techniques and tools from arts, science, science communication, and storytelling (Fig. 1). The three main components were the scientific content (the message to be communicated), the storytelling and metaphors (the verbal way of communicating the message), and creative dance structure (the sensorial way of communicating the message).

\subsection{Scientific contents}

The activity was developed to communicate concepts and processes related to marine and coastal morphodynamics to 10-year-old students attending the fourth grade. In Portugal, the geosciences are an academic discipline of the official primary school curriculum. Nevertheless, geoscience contents are included in the generic discipline of "environmental studies", which includes basic knowledge of science such as the human body, the solar system, monarchy history, earth surface morphology, the water cycle, and protection of the environment. Within this discipline, there is a unit devoted to the sea-land interface.

The activity was comprised of a series of six exercises (Fig. 2) that were preceded by a simplified but accurate scientific explanation adapted to the average expected pedagog- ical level starting with an introduction, followed by a basic geoscience concepts explanation, and enforcing the message with a résumé at the end. The key geosciences concepts were wave, wave size, breaking waves, sand grain, sediment transport, beach dynamics, and seasonality. Waves form when the water surface is disturbed, for example, by wind, earthquakes, or planetary gravitational forces. During such disturbances, energy and momentum are transferred to the water mass and transmitted in the direction of the impelling force (e.g. Carter, 1988). At the shoreline, part of the incoming wave energy is reflected and is propagated back to the open sea very much the way light bounces off a mirror; most of the incoming wave energy, however, is transformed to generate nearshore currents and sediment transport and is ultimately the driving force behind morphological change at the coast (e.g. Masselink and Hughes, 2003). The portion of the coast most familiar to most people is the beach. The beach includes the adjacent seabed below shallow marine waters, which is generally called the nearshore environment until the highest high-tide line. The beach is comprised of nearly anything that can be transported by waves (e.g. Davis, 1996), including predominantly sand but also gravel, mineral and organic, that comes from river discharge, cliff erosion, glacier melting, organic shells production, volcanic activity, and the ocean continental shelf, amongst others (e.g. Anthony, 2014). The exchange of beach sediment between submerged and subaerial portions of the beach is accomplished by onshoreoffshore transport, mainly by waves, but aided sometimes by wind (e.g. Carter, 1988). Beach morphology thus responds to changing wave conditions and has a cyclic behaviour. In many occasions, the cycles are seasonal; wave conditions during winter storms shift sand offshore, whilst calm conditions during the summer induce landward migration of sediments back to upper parts of the beach (e.g. Komar, 1976).

Important associations from this activity are the connections between the atmosphere, ocean, and coast as well as the insight between casual observations that the students make, i.e. their empirical knowledge of the coast, for example, breaking waves, beach width, sand grains, and the science behind it.

The scientific content was divided into three major coastal hydrodynamic and morphodynamics situations: wave generation and propagation, sediment transport, and storm/fairweather conditions. Wind blowing on ocean surface and wave generation were explained not only to elucidate how waves are generated but also to demonstrate the connection between separate environments (atmosphere and the oceans). Wave propagation was used to illustrate energy transference across the ocean surface, opposite to mass transference, and to make the transition from the ocean to the coastal environment until waves break at the shore (Fig. 3). The generation of onshore currents under the presence of waves from the submerged to the subaerial part of the beach was then introduced. Sediment transport by onshore currents was explained as a straightforward effect in the presence of grains in 


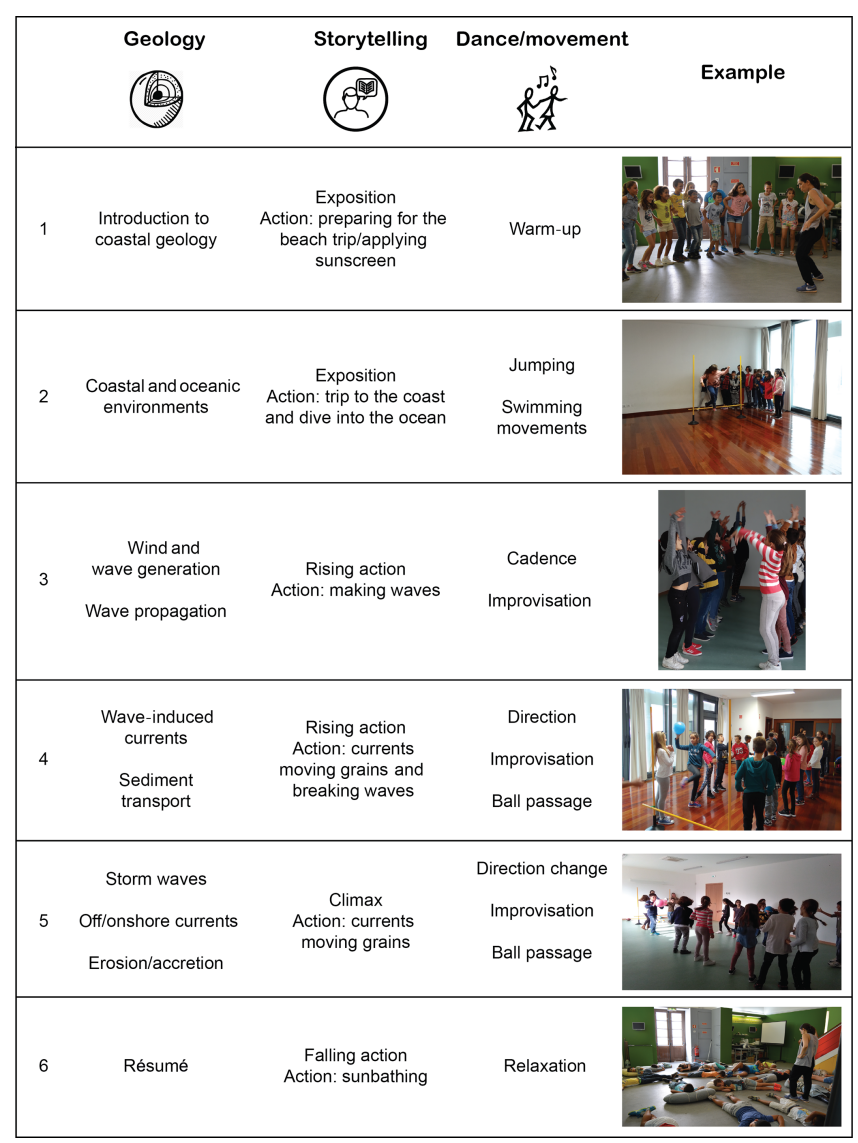

Figure 2. Activity outline: list of scenes (from 1 to 6), related scientific contents, associated storytelling moment, and type of dance movements.

the bottom (lower block diagram and pink arrow on Fig. 4). Here sediment variability, including shape, size, and composition, was introduced in relation to possible sources such as volcanic rocks or coral reefs.

Wave-height variations throughout the year were explained by introducing the concept of storm waves and induced-sediment transport patterns (upper block diagram and pink arrow in Fig. 4). Because onshore currents generated by fair weather were explained, offshore currents and consequently beach erosion did not need an elaborate explanation. The alternation between erosion and accretion, i.e. seasonality of waves and beach morphology depending on wave height, was reinforced as natural occurrences on a natural beach.

\subsection{Storytelling and metaphors}

As in any story, the activity had a theme, settings, scenes, characters, actions, and a narrative arc. In broad terms, the narrative arc is the sequence of action shaped by the exposition, rising action, crisis, climax, and falling action (e.g. Hart, 2011). The theme of coastal dynamics is immediately set in

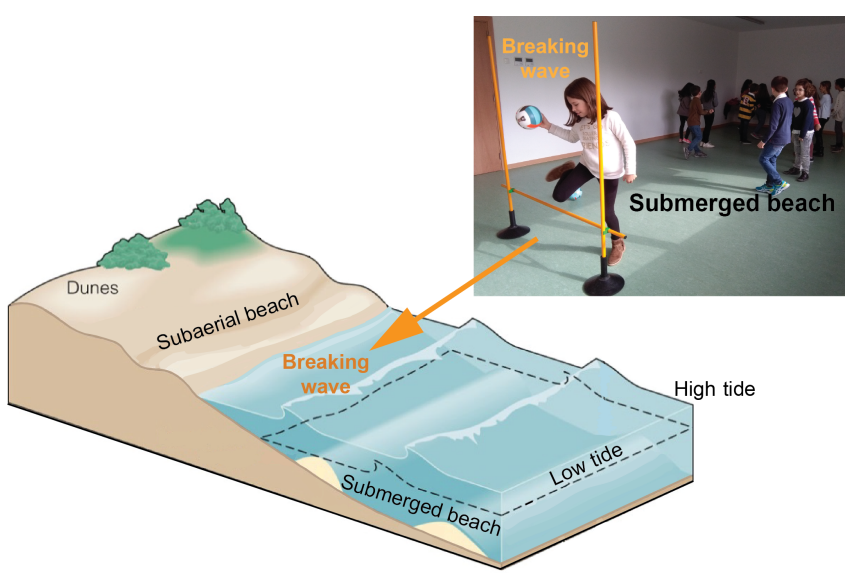

Figure 3. Coastal environments: dunes, subaerial beach, and submerged beach. The photograph shows a breaking wave, with a jump over the yellow horizontal bar representing the position that separates the subaerial from the submerged beach (towards the righthand side, where children are in two rows of propagating waves).

the introduction, when the scientific topic is addressed. The settings, i.e. the natural environments, were built with psychomotricity equipment but mostly appealing to imagination. Psychomotricity is a holistic type of intervention, by means of movement and play, oriented towards humanism and respecting a child's development stage (see, for example, Vetter, 2019). It refers to psychomotor educational interventions (e.g. Perrotta, 2011) but also to therapeutic practices (e.g. Ayres, 2005; Ingwersen et al., 2019) in which there is a relationship between the psyche (mental processes) and motoric activities (physical activities). Typical psychomotor equipment (see European Forum of Psychomotricity, 2016) for children includes colourful hoops, balls, cones, mats, bags, blocks, and poles that can be used in isolation or as frames, tunnels, tracks, climbing sets, or balancing courses.

There were three main settings, namely the deep ocean, the beach under water, and the subaerial beach (Fig. 3). The limit of the subaerial and submerged beach, i.e. the wavebreaking position, was marked with two poles and a horizontal bar, while sediment balls of different sizes, colours, shapes, and textures represented sediments (Fig. 3). The settings/scenarios of the action (marine and coastal environments) were also suggested by specific actions such as diving into the ocean (jump over the horizontal bar), imaginary application of sunscreen, and sunbathing (relaxation; Fig. 4). Characters performed by students were beach users (scenes 1, 2, and 6; Fig. 2) and water particles (scenes 3 to 5; Fig. 2).

The narrative consisted of a set of six practical actions (exercises) that were plotted in a predefined sequence of increasing complexity and excitement (at the beginning of the activity), with a sharp decline to relaxation (at the end of the activity) following the narrative arc (Fig. 2). During scenes 1 and 2 , an exposition to the theme and settings was conducted, obtained by the verbal explanation of the beach topic and 


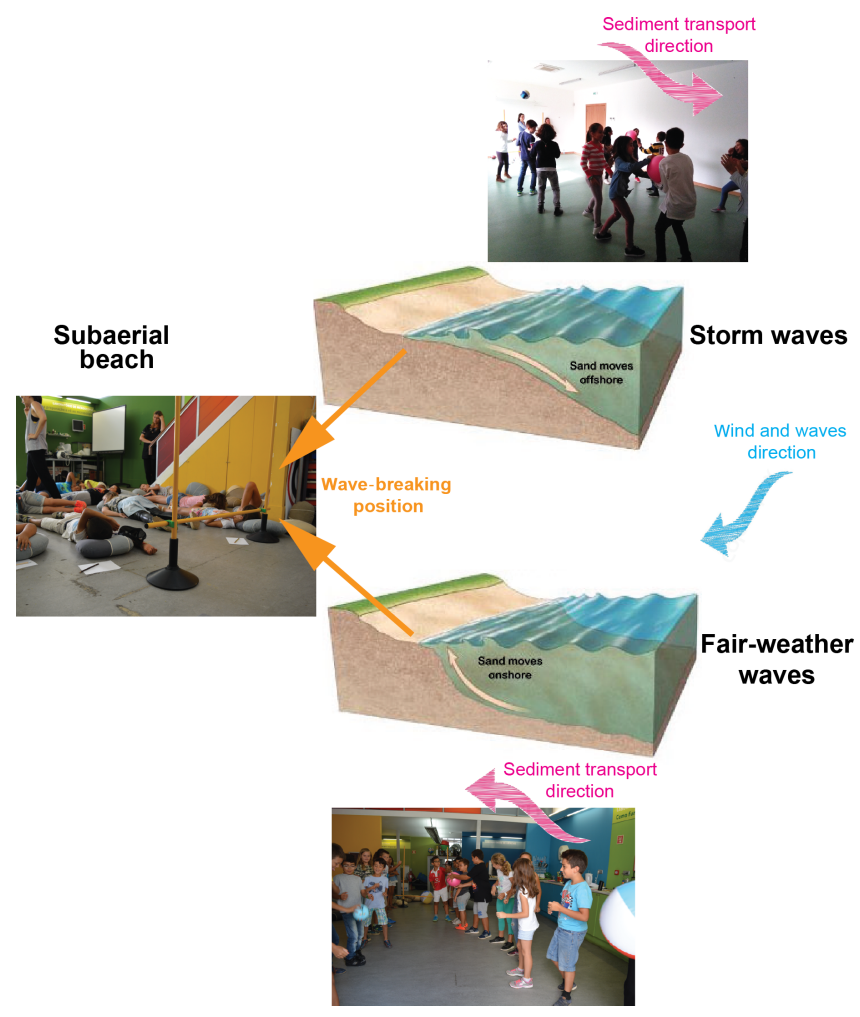

Figure 4. Coastal environments, coastal processes, and metaphors. The image illustrates waves approaching the coast by coming from the right side (blue arrow). The direction of sediment transport (pink arrows on top of photographs) was embodied by the direction of the hand-to-hand ball (representing sediment grains) passage during storms (top right) and fair weather (bottom right). The wavebreaking position is represented in the room by two yellow vertical poles and a horizontal bar, with the subaerial beach towards the lefthand side (where children are resting in the middle photograph).

by suggesting a sequence of actions that mimic a trip to the beach and finishing with the dive into the ocean; students (actors) embodied beach users. From scenes 3 to 4, settings were kept but characters were changed, and actors embodied water particles instead of beach users. The actions involved exercises of increasing complexity, reflecting a rise in action, as they impersonated water particles on the sea surface and then water particles as a current that transported grains to the shore. In scene 5, the climax was attained when storm waves reached the coast in several moments, and sediments could move in opposite directions. During scene 6, characters returned to beach users again; actors came out of the ocean and sunbathed, in a falling action (Figs. 2 and 4).

\subsection{Creative dance structure}

According to Gilbert (2015), creative dance is a dance form that combines the mastery of movement with the artistry of expression. In creative dance, children generate, vary, and manipulate movement by using the elements of dance through the process of improvisation (Cone and Cone, 2012). The basic movement concepts used here derive from the Laban movement analysis. Rudolf Laban's (1897-1958) philosophy was based on the belief that the human body and mind are one and are inseparably fused (e.g. Newlove and Dalby, 2004). It was Laban's firm belief that it is the birthright of every person to dance - not just trained dancers or folk dancers and the like but all human beings (Newlove and Dalby, 2004). Laban movement analysis is a method to describe and analyse human movement and to establish a notation system with precision and clarity (von Laban, 1963). Laban's ideas have been picked up, reinterpreted, evolved, and ramified, for example, to dance movement psychotherapy (e.g. Best, 2008), programmes for individuals affected by complex needs (e.g. Price, 2008), and creative dance (e.g. Gilbert, 2015). Structure and elements used here were also based on techniques described by several dance educators (Landalf, 1997; Carline, 2011; Cone and Cone, 2012; Abbott, 2013; Gilbert, 2015). The creative dance unit focused on the effort concepts of time (fast/slow), space (direction), and flow (bonded/free). A typical session of creative dance is comprised of the following: (1) warming up, (2) exploring the concept, (3) developing skills, (4) creating, and (5) cooling down (Gilbert, 2015).

During the first exercise (scene 1, applying sunscreen), there was a warm-up of muscles and mobilization of articulations through light aerobic movements such as bending, twisting, and curling (see dance/movement in Fig. 2). During the second exercise (scene 2), students jumped over the obstacle (diving into the sea; Fig. 3) in turns and made swimming free movements across the space. In the third exercise (scene 3), students stood in two lines, facing each other, reproducing several waves with the body undulating, with arms up, in a cadence. The movement was repeated in a cadence of dance improvisation. During the fourth exercise/scene, the two rows of students performed dance improvisation while passing different balls (representing sediment transport) in the direction of the obstacle (the subaerial beach; Fig. 4), jumping to mimic breaking waves. In the fifth exercise/scene, students applied the same type of movements as in the fourth exercise/scene but listened to a different soundtrack; the music changed in intensity and the balls moved to the obstacle when the music's intensity was lighter and moved in the opposite direction when the music was louder and more intense to represent fair-weather waves and storm waves, respectively. During the sixth exercise/scene, students spread through the available space and rested on the floor, while relaxing, and sensory stimulation was induced by speech and appealed to sensations felt while sunbathing (sea smell, warmth on the skin, wind sensation, and sand grains under the body).

Soundtracks included music/sounds with lyrics alluding to the sea (exercises 1,2, and 6), soundtracks from animation movies (exercise 2), sounds from nature (wind in exercise 3 and waves in exercise 6), a Portuguese traditional theme (ex- 
ercise 1), classical music (exercise 5), and pop music (exercise 4). The activity was called "The Sea Rolls the Sand", which is the name of a Portuguese traditional song. All musical themes had easy rhythmic and melodic compositions.

\section{3 "The Sea Rolls the Sand" activity implementation}

\subsection{Performing opportunities and institutional framework}

The activity was performed six times within national and international initiatives. During the first two times, the sessions were included in the activity of the European Researchers' Night on 29 September 2017. These sessions took place in the educational laboratory of the Tavira Ciência Viva Science Centre, which was emptied as much as possible to create space for physical activities. The other four sessions were included in a national initiative, Science and Technology Week, on 23 and 24 November 2017. These sessions took place at three (private and public) schools in the classrooms and in the gym.

Overall, 112 students participated in the activity, divided according to their original school classes, that varied between 15 and 22 students per session. Two classes in small schools in rural areas included students from different grades, namely first and fourth, in one case, and third and fourth, in another case. The Tavira municipality had 323 students attending fourth-grade classes or mixed classes divided into 16 classes (with 13 to 26 students per class). Therefore, about $35 \%$ of all fourth-grade students from the municipality participated in the activity.

All students in the class participated, including children with cognitive impairment, attention deficit disorder, amblyopia, light autism, hyperactivity, and dyslexia.

Teachers assisted all sessions and had no intervention in the scientific topics or session alignment; however, occasional teacher interference occurred to assist with behaviour management of the class. In one of the sessions, a teacher assigned to cognitive impairment students was also present, but no interference took place. There was no discussion or presentation in advance with the teachers about the sessions' specific methods and contents. Teachers volunteered to participate solely based on the information on the general topic. They were briefed about the need for an empty room and that children should be wearing clothes appropriate for physical activity.

\subsection{Activity evaluation by participants}

At the end of the activity, with children still lying all over the floor, small enquiries were distributed to obtain an anonymous evaluation. Questions concerned the following: (1) if they enjoyed the activity; (2) if they liked the movements; (3) if they liked the music; (4) how they prefer to learn science; (5) if they think they learnt something new; and (6) if

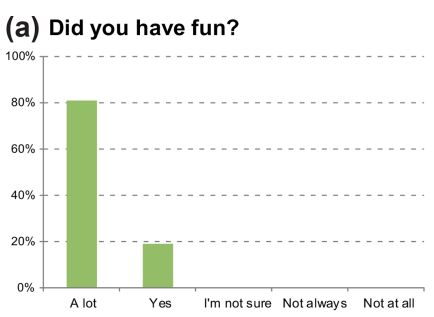

(b) How do you prefer to learn science?

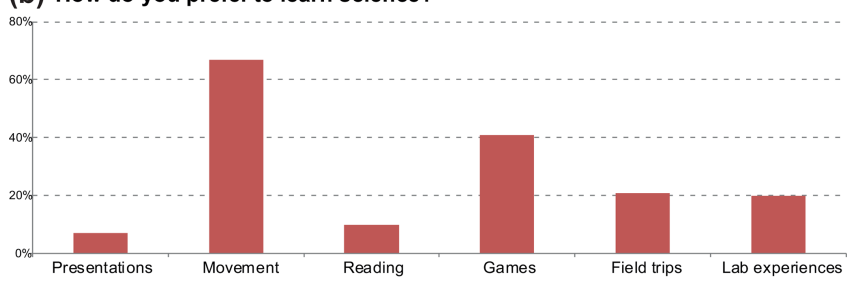

(c) Would you like to repeat it?

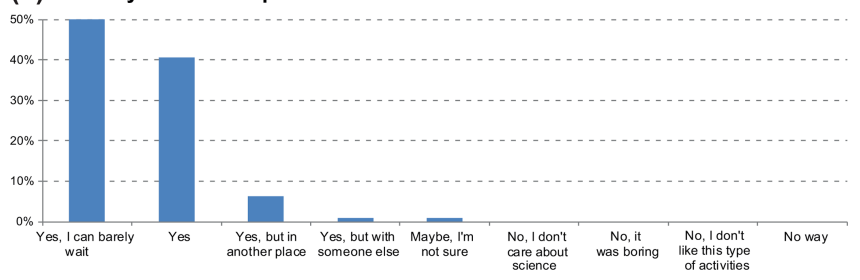

Figure 5. Results of enquiries for some of the questions. Note that for the question about how they prefer to learn about science multiple responses were allowed, and the vertical axis is the number of responses and not a percentage.

they would like to repeat it and, if so, with another person or in another place.

From the 112 students that responded to the enquiries, there was an even distribution of boys and girls (51\% were girls). Results showed that all children enjoyed themselves and $80 \%$ enjoyed it a lot (Fig. 5a). About $75 \%$ liked the movements a lot and only $1 \%$ was not sure about this.

Only one student did not like the music selection. After anonymously filling in the enquiry, the student stated: "I hate classical music."

According to the enquiry's responses, these children prefer to learn science through movement and games, although field trips and laboratory experiments were also frequently selected (20 out of 112; Fig. $5 \mathrm{~b}$ ). When questioned about how much they learnt from the activity, $35 \%$ answered that they learnt something new and $60 \%$ answered that they learnt a lot, with $5 \%$ stating they already knew everything. A total of $99 \%$ of children want to repeat the activity, but $20 \%$ of the students from one of the schools said they preferred to do it elsewhere (Fig. 5c).

The time constraints and the lack of personnel to ensure the children's supervision did not allow for a proper quantitative assessment of the schoolteachers' opinions. Nevertheless, teachers expressed that "the activity was very nice and good for children of this age". Additionally, some teachers 
were concerned about some children's inability to follow the scientific content or not having appropriate behaviour all the time.

The researcher conducting and researchers assisting the activity observed that these children living in coastal areas, despite having limited scientific background on coastal geology, have plenty of empirical experience of the coast.

\section{Innovation, insights, and limitations of the interdisciplinary fusion}

The observations made throughout the activities showed that the developed and performed activity has pros and cons in relation to more traditional forms of informal education.

The main hypothetical risks associated with the methodology application are as follows: the detachment of children from the activity, the disinterest of children in the scientific subject, the lack of understanding of children about the message, the feeling of shame during the dance exercises, and the little time they had to consolidate the scientific content through reflection. Some of these risks could not be directly observed and measured with the results of the enquiries. The size of the sample (six sessions; 112 students) was considered sufficient for a pilot test, attesting to its feasibility, age appropriacy, content relevance, and teachers' interest and acceptance. However, the sample size and composition were insufficient to analyse other factors. Comprehensive analysis and conclusions would require a comparison between the impact of this activity and another science communication format covering the same scientific topics and age group. The lack of an evaluation plan was the main shortcoming of this work.

The main opportunity associated with the methodology application is engaging children with science concepts by focusing attention (demonstrated by Kim, 2012, as the first step towards engagement) on the affective domain of learning and showing emotions through movement. Furthermore, it may have the capacity to promote ocean literacy. Nevertheless, a measurable assessment in future implementations and studies will be crucial in order to validate the impact of such methods. The innovation of the presented activity is the enlargement of the science communication strategies whereby scientists also communicate through creative dancing.

Insights from the activity development and performance can be summarized as follows:

- The interdisciplinary solution seems to be adequate as a general approach to solving complex issues with the complex issue here being a generalized disconnection between students and geosciences. The appeal to conceptual understanding, rather than memorization, in geosciences (e.g. names of minerals and rocks, types of volcanoes and their location, and names of geomorphological features) aligns with the most necessary improvements in curricular guidelines identified by
Afonso et al. (2013) for Portuguese education of sciences. The storytelling technique of content sequencing versus a plain sequence of contents looks like a successful technique for engagement with the activity.

- The emotional involvement in the presence of music seems to effectively encourage engagement, active participation in the present activity, and willingness to take part in different experiences in the future. Several positive emotions and feelings were promoted during the activity, evolving from anticipation, pleasure, surprise, and enjoyment to excitement and then serenity and relaxation. The assessment of emotional states was based on local observations by the persons conducting and assisting/observing, both directly and by revising photos and videos. Observation notes included the record of facial expressions, silence/talking/laughter, and body language (heads follow/do not follow the person explaining, readiness/delayed movement, peak/indifference, jumping and frenzy in anticipation/apathy, and inertia or yawning). It seems fair to suppose that the pleasant memories of the playful visits to the beach evoked during the activity (vacations, playing, and freedom) became also associated with science and learning. The movement and improvisation is effective in creativity stimulation, self-expression, and stress release, thus being aligned with the 21 st century educational orientations (as demonstrated by Cone and Cone, 2012). Moreover, the activity is innovative yet not supported by screens. During the early stages of the activity, shyer children tended to be reluctant to participate, to be very self-conscious, and to make small movements as a consequence. As the activity advanced, they became more open and engaged with the proposed exercises.

- The activity was able to mitigate some students' exclusion factors. Inclusion of students with diverse and special needs in the classroom has been a major focus in education over the past 30 years (Villanueva et al., 2012). The children's position in the space (spread out or in two lines, facing each other), participating in chain sequencing, allows students with some degree of impairment to engage in the activity. Additionally, the organization of the activity for school classes, rather than an activity for families, assures the presence of children who would not participate otherwise.

- The social benefits of this type of activity can potentially include team building and students learning selfdiscipline, gaining an appreciation for other movement styles, and discovering the value of individual differences through creative exploration and problem solving. Socially, children enjoy interacting with others through movement (Cone and Cone, 2012). They laugh and talk with each other while sharing an experience that is fun and rewarding. The use of free (not choreographed) 
movements and balls can break the stereotype of "dancing is for girls", thus promoting gender equality. These are values identified in creative dance (e.g. Landalf, 1997; Carline, 2011; Cone and Cone, 2012) that can be incorporated into science communication.

- A thorough evaluation of science communication initiatives is essential to enable the identification of whether long-term objectives are being met; it can help to make the iteration of science communication initiatives more efficient and can also highlight areas that need further strengthening (Illingworth, 2017). There was anecdotal evidence of increased familiarity and comfort with geosciences (e.g. use of scientific terminology by students towards the end of the activity; processes introduced by researchers in the exposition scenes were translated to actions by students in the climax scene), which may have been the result of the brief explanation at the beginning of the section being reinforced by the physical exercises. In this study, due to the sporadic nature of the activity, within a major event it would be difficult to establish a baseline of the children's knowledge prior to the intervention. After this session, the same students were involved in a science club devoted to topics of coastal geosciences in which lab experiences and a field trip were made.

- In future, activities such as the European Researchers' Night 2020 and following an improved programme should incorporate an assessment of the students' interest in and understanding of the scientific subject in comparison to other science communication methods. This entails the development and testing of a specific impact assessment design. A future evaluation plan could include the following: (1) pre-activity data on knowledge of coastal morphodynamics - this may be done prior to the activity or be included interactively in the introductory section by asking for experiences of waves/shorelines; (2) pre-activity data on how pupils prefer to learn science and on how students with special needs interact with other students; (3) pre- and post-data on the science capital of the teachers and pupils; (4) teachers' and outside observers' evaluations of emotional states during the activity; (5) evaluation of impacts on the researchers and creative partners; (6) follow-up data on the students' understanding and retention of the principles being communicated at, e.g., $14 \mathrm{~d}$ or another time period deemed suitable post-event; (7) follow-up with teachers in order to assess the impact of the activity on team building, self-discipline, and appreciation for each other's differences. At first, qualitative methods may be used to identify what outcomes are emerging; later, quantitative methods may be used to measure the strength of the outcome or what proportion of participants experience the different outcomes (Grant, 2011).
- This activity was a first step towards the setting of transdisciplinary activities in geosciences that can meet a rather difficult balance between scientific accuracy, stimulation of creativity, art and science bonding, integration of body-mind principles, and promotion of inclusion of students with special needs.

\section{Final remarks}

A science communication activity for primary-grade children was developed and implemented through an innovative approach, by combining coastal science concepts with storytelling and creative dance techniques. The way scientific concepts were translated into the dance class structure was described thoroughly to allow science communicators the chance to look behind the scenes at creative dance.

The dance's ability to directly improve overall learning skills (which is at least questionable, according to Keinänen et al., 2000) was not the purpose here. The proposal was to use art (dance to exemplify) to promote science engagement through emotional involvement, creativity, and sensory stimulation. The presence and acknowledgement of emotions is another way that the practice of science communication can overflow expectations, and models of it and something else would be valuable to notice more in science communicators' analysis (Davies and Horst, 2016).

The proposed activity has the potential to promote social inclusion of children with special needs and physical impairment as students with these impairments actively participated in the activity in a positive way. The theme of social inclusion in the science communication field is not new; the political value of science communication was explicit in many cornerstones of the history of this field (Massarani and Merzagora, 2014). Nevertheless, the exclusion from science communication activities is not only a statistical fact but also a neglected matter in communication research (Dawson, 2018).

Regarding the activity impacts, enquiry results showed that all children seemed to enjoy themselves. Nevertheless, the improvement of geoscience literacy was not measured. Yet, science communication paradigms have shifted from science literacy ("the deficit model") to science and society (e.g. Bauer, 2008). This activity is aligned with the most recent paradigms in which communication is interactive and constructive with emphasis on dialogue, deliberation, participation, and empowerment (Davies and Horst, 2016). It may contribute to the students' "science capital" (as defined by Archer et al., 2015) in the following dimensions: (i) science-related attitudes, values, and dispositions - because science was approached in an enjoyable and engaging way, with the potential to have increased openness to geosciences; (ii) knowing science-related jobs - because both people conducting the activity were researchers and were introduced that way at the beginning; (iii) making science relevant to the everyday lives of students - because geoscience 
study objects are part of students' lives as coastal inhabitants, and they are very familiar with barrier islands; and (iv) the potential for increased science literacy (evidenced by the use of scientific terminology towards the end of the activity).

Increased science capital or science literacy from this activity is a supposition based on qualitative observations and suppositions; an effort to a more evidence-based science communication approach (Jensen and Gerber, 2020) and subsequent evaluation is needed, and this is a shortcoming of this pilot programme.

The addressed geoscience topics and other adopted art forms can be combined in future activities in a number of ways; for example, we can foresee as adequate, innovative, and engaging the combination of volcanology and music (e.g. types of volcanoes and volcanic rocks can be approached with percussion instruments and rhythms); climate change and drama (e.g. impacts of heat waves can inspire a play); and oceanography and poetry (e.g. waves and currents around the world can inspire poems). An existing case of geoscience and art is the work of the artist Laura Moriarty (see http://www.lauramoriarty.com/, last access: 26 June 2020), who combined plate tectonics and sculpture (faults and bedding planes are approached and appreciated as blocks of a sculpture). This almost endless number of combinations, on top of the aesthetical value of earth-science objects, from a desert landscape to a mineral, a geyser, satellite imagery, a canyon, or a rocky shore, to name just a few, is an asset worthy of further exploration in STEAM science communication.

Data availability. The dataset of the enquiry results analysed within this paper is freely available via Figshare: https://doi.org/10.6084/m9.figshare.12574205.v1 (Matias et al., 2020).

Author contributions. AM conceptualized the programme, performed the programme, analysed the results, wrote the original draft, and reviewed and edited the paper. ARC performed the programme and reviewed and edited the paper. AAR and RB managed the programme, communicated with the schools and reviewed and edited the paper.

Competing interests. The authors declare that they have no conflict of interest.

Acknowledgements. The authors wish to thank the two reviewers for their comments and contributions, particularly the second reviewer, who proposed a future evaluation plan for the activity.

Financial support. This research was supported by the Fundação para a Ciência e a Tecnologia (FCT) as part of the EVREST project (grant no. PTDC/MAR-EST/1031/2014). Ana Matias was supported by FCT (grant no. IF/00354/2012), and A. Rita Carrasco and Ana A. Ramos were supported by FCT (contract nos. DL 57/2016/CP1361/CT0002 and DL 57/2016/CP1432/CT0001, respectively).

Review statement. This paper was edited by Sam Illingworth and reviewed by two anonymous referees.

\section{References}

Abbott, M.: Beyond Movement, Mathematics dance curriculum, Dance Equa., CreateSpace Independent Publishing Platform, ISBN-13: 978-1496067647, 188 pp., 2013.

Afonso, M., Alveirinho, D., Tomás, H., Calado, S., Ferreira, S., Silva, P., and Alves, V.: Que ciência se aprende na escola?, Fundação Francisco Manuel dos Santos, Lisbon, Portugal, 2013.

Anthony, E. J.: Environmental control: geology and sediments, in: Coastal environments and global change, edited by: Masselink, G. and Gehrels, R., John Wiley \& Sons Ltd. and AGU, 52-78, 2014.

Archer, L., Dawson, E., Dewitt, J., Seakins, A., and Wong, B.: Science Capital: A Conceptual, Methodological, and Empirical Argument for Extending Bourdieusian Notions of Capital Beyond the Arts, J. Res. Sci. Teach., 52, 922-948, https://doi.org/10.1002/tea.21227, 2015.

Ayres, A. J.: Sensory integration and the child: 25th Anniversary Edition, Western Psychological Services, Los Angeles, USA, 2005.

Baron, N.: Escape from the ivory tower: a guide to making your science matter, Island Press, 2010.

Bauer, M. W.: Paradigm change for science communication: commercial science needs a critical public, in: Communicating science in social contexts, edited by: Cheng, D., Claessens, M., Gascoigne, T., Metcalfe, J., Schiele, B., and Shi, S., Springer, 7-25, 2008.

Best, P.: Creative tension: dance movement psychotherapists shaping Laban's ideas, in: The dynamic body in space, edited by: Preston-Dunlop, V. and Sayers, L.-A., Dance Books, 20-27, 2008.

Brown, K., Eernstman, N., Huke, A. R., and Reding, N.: The drama of resilience: Learning, doing, and sharing for sustainability, Ecol. Soc., 22, https://doi.org/10.5751/ES-09145-220208, 2017.

Bultitude, K.: The Why and How of Science Communication, in: Science Communication, edited by: Rosulek, P., European Comission, Pilsen, 1-18, 2011.

Cachapuz, A. F.: Arte e ciência no ensino das ciências, Interacções, 106, 95-106, https://doi.org/10.25755/int.6372, 2014.

Carline, S.: Lesson plans for creative dance: connecting with literature, arts, and music, Human kinetics, USA, 2011.

Carter, R. W. G.: Coastal Environments: An Introduction to the Physical, Ecological and Cultural Systems of Coastlines, Academic Press, 1988.

Chang, M.: Communicating environmental science through art?: scope, applications, and research agenda, University of Washington, 2015. 
Cone, T. R. and Cone, S. L.: Teaching children dance, 3rd Edn., Human kinetics, Champaign, IL, USA, 2012.

Davies, S. and Horst, M.: Science Communication. Culture, Identity and Citizenship, Palgrave Macmillan UK, London, UK, 2016.

Davis, R. A.: Coasts, Prentice-Hall, Inc., New Jersey, USA, 1996.

Dawson, E.: Reimagining publics and (non) participation: Exploring exclusion from science communication through the experiences of low-income, minority ethnic groups, Public Underst. Sci., 27, 772-786, https://doi.org/10.1177/0963662517750072, 2018.

European Forum of Psychomotricity: Glossary Psychomotor Paradigm, European Forum of Psychomotricity, 16 pp., available at: https://psychomot.org/ (last access: 26 June 2020), 2016.

Friedman, A. J.: Reflections on Communicating Science through Art, The Museum Journal, 56, 3-9, https://doi.org/10.1111/cura.12001, 2013.

Gabrys, J. and Yusoff, K.: Arts, sciences and climate change: Practices and politics at the threshold, Sci. Cult., 21, 1-24, https://doi.org/10.1080/09505431.2010.550139, 2012.

Gilbert, A. G.: Creative dance for all ages, Human kinetics Publishers, Champaign, IL, USA, 2015.

Grant, L.: Evaluating success: how to find out what worked (and what didn't), in: Successful science communication, Telling it like it is, edited by: Bennett, D. J. and Jennings, R. C., Cambridge University Press, 403-422, 2011.

Gravina, T., Muselli, M., Ligrone, R., and Rutigliano, F. A.: SUstaiNability: a science communication website on environmental research, Nat. Hazards Earth Syst. Sci., 17, 1437-1446, https://doi.org/10.5194/nhess-17-1437-2017, 2017.

Hart, J.: Storycraft: the complete guide to writing narrative nonfiction, The University of Chicago Press, 2011.

Hayes, J. C. and Kraemer, D. J. M.: Grounded understanding of abstract concepts: The case of STEM learning, Cognitive Research: Principles and Implications, 2, https://doi.org/10.14219/jada.archive.1952.0112, 2017.

Heras, M. and Tàbara, J. D.: Let's play transformations! Performative methods for sustainability, Sustain. Sci., 9, 379-398, https://doi.org/10.1007/s11625-014-0245-9, 2014.

Illingworth, S.: Delivering effective science communication: advice from a professional science communicator, Semin. Cell Dev. Biol., 70, 10-16, https://doi.org/10.1016/j.semcdb.2017.04.002, 2017.

Ingwersen, K. G., Vobbe, J. W., Pedersen, L. L., Sørensen, L., and Wedderkopp, N.: Effect of psychomotricity in combination with 3 months of active shoulder exercises in individuals with chronic shoulder pain: primary results from an investigator-blinded, randomized, controlled trial, Arch. Phys. Med. Rehab., 100, 21362143, https://doi.org/10.1016/j.apmr.2019.05.032, 2019.

Jensen, E. A. and Gerber, A.: Evidence-based science communication, Front. Commun., 4, https://doi.org/10.3389/fcomm.2019.00078, 2020.

Keinänen, M., Hetland, L., Winner, E., and Keinanen, M.: Teaching Cognitive Skill through Dance: Evidence for near but Not Far Transfer, J. Aesthet. Educ., 34, 295-306, https://doi.org/10.2307/3333646, 2000.

Kim, H.-S.: Engagement: the key to the communicative effectiveness of science and ideas, chap. 18, in: Science communication in the world: practices, theories and trends, edited by: Schiele, B., Claessens, M., and Shi, S., Springer, 269-279, 2012.
Komar, P. D.: Beach processes and sedimentation, Prentice-Hall, Inc., Englewood Cliffs, New Jersey, 1976.

Kombiadou, K., Matias, A., Carrasco, R., Ferreira, Ó., Costas, S., and Vieira, G.: Towards Assessing the Resilience of Complex Coastal Systems: Examples from Ria Formosa (South Portugal), J. Coast. Res., 85, 646-650, https://doi.org/10.2112/SI85-130.1, 2018.

Kombiadou, K., Costas, S., Carrasco, A. R., Plomaritis, T. A., Ferreira, Ó., and Matias, A.: Bridging the gap between resilience and geomorphology of complex coastal systems, Earth-Sci. Rev., 198, 102934, https://doi.org/10.1016/j.earscirev.2019.102934, 2019a.

Kombiadou, K., Matias, A., Ferreira, Ó., Carrasco, A. R., Costas, S., and Plomaritis, T.: Impacts of human interventions on the evolution of the Ria Formosa barrier island system (S. Portugal), Geomorphology, 343, 129-144, https://doi.org/10.1016/j.geomorph.2019.07.006, 2019b.

Landalf, H.: Moving the earth: teaching earth science through movement for grades 3-6, Smith and Lyme, USA, 1997.

Lopes, M. M.: Intertwined artistic practices?: critical remarks on collaboration across fields of knowledge, MIDAS, 5, https://doi.org/10.4000/midas.856, 2015.

Martinez-Conde, S. and Macknik, S. L.: Opinion: Finding the plot in science storytelling in hopes of enhancing science communication, P. Natl. Acad. Sci. USA, 114, 8127-8129, https://doi.org/10.1073/pnas.1711790114, 2017.

Massarani, L. and Merzagora, M.: Socially inclusive science communication, J. Sci. Commun., 13, https://doi.org/10.22323/2.13020301, 2014.

Masselink, G. and Hughes, M.: Introduction to Coastal Processes and Geomorphology, Hodder Arnold, 2003.

Matias, A., Carrasco, A. R., Ramos, A. A., and Borges, R.: Data "Engaging children in geoscience through storytelling and creative dance", Figshare, https://doi.org/10.6084/m9.figshare.12574205.v1, 2020.

McCallie, E., Bell, L., Lohwater, T., Falk, J. H., Lehr, J. L., Lewenstein, B. V., Needham, C., and Wiehe, B.: Many experts, many audiences: public engagement with science and informal science education, A CAISE Inquiry Group Report, Washington, DC, 2009.

Mesure, S.: The CreScENDO Project: final report for NESTA, London, 2007.

Newlove, J. and Dalby, J.: Laban for all, Nick Hern Book, London, UK, 2004.

Pedrozo-Acuña, A., Favero Jr., R. J., Amaro-Loza, A., MocvaKurek, R. K., Sánchez-Peralta, J. A., Magos-Hernández, J. A., and Blanco-Figueroa, J.: An innovative STEM outreach model (OH-Kids) to foster the next generation of geoscientists, engineers, and technologists, Geosci. Commun., 2, 187-199, https://doi.org/10.5194/gc-2-187-2019, 2019.

Perrotta, F.: A project for the education psychomotor for developmental age, Journal of Physical Education and Sport, 11, 102113, 2011.

Price, D.: Laban's Art of Movement; a basis for a creative, holistic movement programme for individuals affected by complex needs, ASD (Autistic Spectrum Disorders) and behaviour which challenges, in: The dynamic body in space, edited by: PrestonDunlop, V. and Sayers, L.-A., Dance Books, 190-194, 2008. 
Santoro, F., Selvaggia, S., Scowcroft, G., Fauville, G., and Tuddenham, P.: Ocean literacy for all - A toolkit, United Nations Educacional, Scientific and Cultural Organization, Paris, France (IOC Manuals and Guides, 80), 2017.

Schwartz, B.: Communicating Science through the Performing Arts, Interdiscipl. Sci. Rev., 39, 275-289, https://doi.org/10.1179/0308018814Z.00000000089, 2014.

von Laban, R.: Modern educational dance, MacDonald and Evans, London, 1963.

Von Roten, F. C. and Moeschler, O.: Is art a good mediator in a Science Festival?, J. Sci. Commun., 6, https://doi.org/10.22323/2.06030202, 2007.
Varelas, M., Pappas, C. C., Tucker-Raymond, E., Kane, J., Hankes, J., Ortiz, I., and Keblawe-Shamah, N.: Drama activities as ideational resources for primary-grade children in urban science classrooms, J. Res. Sci. Teach., 47, 302-325, https://doi.org/10.1002/tea.20336, 2010.

Vetter, M.: Receptions of efficacy in research of psychomotricity: Why Kavale/Mattson's study was not helpful and reflections about how to do better!, European Psychomotricity Journal, 11, 3-18, 2019.

Villanueva, M. G., Taylor, J., Therrien, W., and Hand, B.: Science education for students with special needs, Stud. Sci. Educ., 48 , 187-215, https://doi.org/10.1080/14703297.2012.737117, 2012.

Wigfall, M. Z.: The Arts?: Building A Foundation To Increase Science Literacy Skills For Urban Youth, University of Missouri-St. Louis, 2015. 